\title{
Bronchoalveolar lavage fluid glutathione in intubated premature infants
}

\section{Royal Postgraduate Medical School, Hammersmith Hospital, London W12 ONN, \\ Department of Paediatrics and Neonatal Medicine Jonathan Grigg \\ Michael Silverman}

Department of Clinical Pharmacology Alan Barber

Correspondence to: Dr Silverman.

Accepted 11 January 1993

\begin{abstract}
Lower concentrations of uncorrected glutathione in the bronchoalveolar lavage fluid were found on the first day of life in seven infants who subsequently developed chronic lung disease when compared with 27 infants who did not require supplemental oxygen at 36 weeks' postconceptional age. The concentration of glutathione on the first day was independent of gestational age. These preliminary results suggest that glutathione accumulates in the lung epithelial lining fluid of preterm infants and that a relative deficiency may predispose to lung injury.

(Arch Dis Child 1993; 69: 49-51)
\end{abstract}

Neonatal chronic lung disease (CLD) results from the vulnerability of the preterm lung to a range of insults including oxygen and barotrauma. ${ }^{1}$ Pulmonary injury can be mediated by oxygen derived reactive species (free radicals) and their production is increased by high concentrations of oxygen, ${ }^{2}$ reperfusion injury, ${ }^{3}$ and activated neutrophils. ${ }^{2}$ Although these conditions exist in the ventilated premature lung, the importance of free radical damage in the development of CLD is not known.

The most destructive species is the hydroxyl radical and its intracellular formation is, in part, prevented by glutathione (glutamylcysteinylglycine). In animal models, intracellular depletion of pulmonary glutathione enhances oxidant toxicity. ${ }^{4-6}$ Additionally, glutathione accumulates in the epithelial lining fluid of the adult human lung in concentrations up to 100 -fold those of the plasma and this may serve as a first line of defence against environmental oxidants. $^{7}$ Increasing the glutathione in epithelial lining fluid by intratracheal administration of glutathione reduces oxidant damage in mice, ${ }^{4}$ but whether this is a result of its extracellular activity per se is unknown.

There are no data on the presence of glutathione in the epithelial lining fluid of newborn babies. We aimed to establish glutathione concentrations in bronchoalveolar lavage fluid (BALF) of intubated infants born at $<35$ weeks' gestation and to compare concentrations between those with CLD with those with a clinically normal pulmonary outcome.

\section{Subjects and methods}

Intubated infants born at $<35$ weeks' gestation irrespective of initial respiratory diagnosis were studied. No procedures apart from those required for normal clinical care were performed. Infants were lavaged on the first and fifth day of life and were divided into three groups. (1) No supplemental oxygen requirement at 36 weeks' postconceptional age (group with no CLD). (2) Supplemental oxygen requirement at 36 weeks' postconceptional age with radiological or postmortem evidence of bronchopulmonary dysplasia after 28 days of age (group with CLD). (3) Death before 28 days of age. No infant received surfactant.

BALF was obtained by a 5 French suction catheter (with end and side holes) situated in the right main bronchus. Two aliquots of $1 \mathrm{ml} / \mathrm{kg}$ normal saline were instilled and BALF aspirated into a sputum trap. After determining white and red cell concentrations by haemocytometer, cells were removed by centrifugation (400 $g \times 6$ minutes). Samples were excluded if the red cell concentration was $>5.0 \times 10^{8} / 1$ or if haemolysis was visible after centrifugation. The supernatant was respun ( $8000 \mathrm{~g} \times 6$ minutes) and stored at $-80^{\circ} \mathrm{C}$.

BALF glutathione (reduced +oxidised) was assayed by a glutathione reductase recycling assay. ${ }^{8}$ BALF was mixed with glutathione oxidoreductase, dithionitrobenzene, and NADPH (Sigma Chemicals) and the rate of increase in optical density recorded at 413 $\mathrm{nm}$. In this assay, all glutathione is converted to the oxidised form. Results were expressed in terms of reduced glutathione equivalents by assuming that the concentrations of reduced glutathione in BALF are twice those of the assayed oxidised concentration. BALF protein was determined by the bicinchoninic acid assay (Pierce Chemical) with a standard range of $0 \cdot 1-1 \cdot 2 \mathrm{mg} / \mathrm{ml}$. Storage at $-80^{\circ} \mathrm{C}$ did not alter glutathione values.

\section{STATISTICAL ANALYSIS}

All values are expressed as mean and range. Glutathione and glutathione/mg protein concentrations were $\log _{10}$ transformed before analysis. Differences between groups were tested by Student's $t$ test and correlations performed using Pearson's correlation coefficent.

\section{Results}

Forty seven infants were lavaged: 27 without CLD, seven with CLD, and 13 died $<28$ days. Age at death in the latter group ranged from 1 to 10 days. There was insufficient sample volume for protein analysis in seven cases. There was no correlation between gestation and glutathione on the first day corrected $(r=0.02, \mathrm{n}=40)$ or uncorrected $(r=0.01$, $\mathrm{n}=47$ ) for protein. 
A
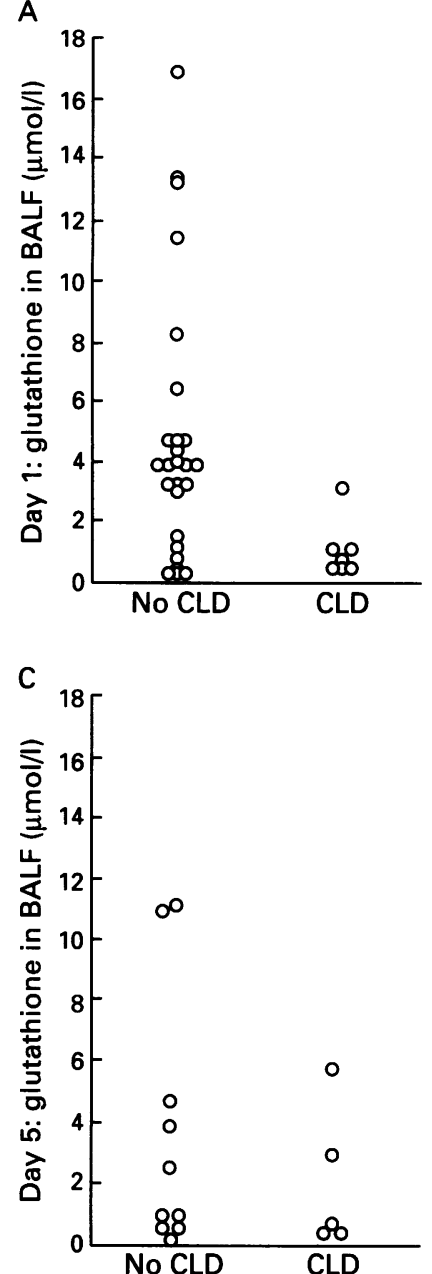

B

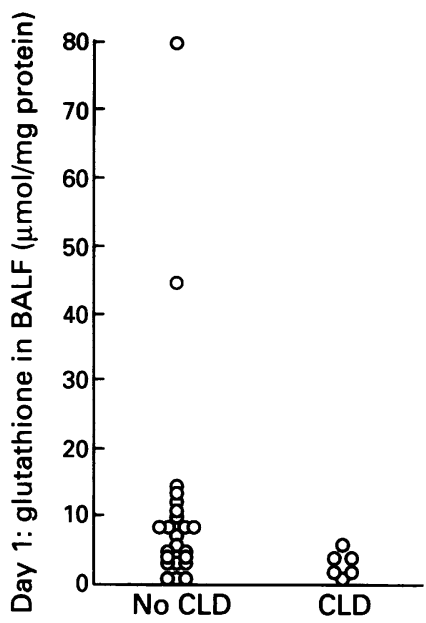

D

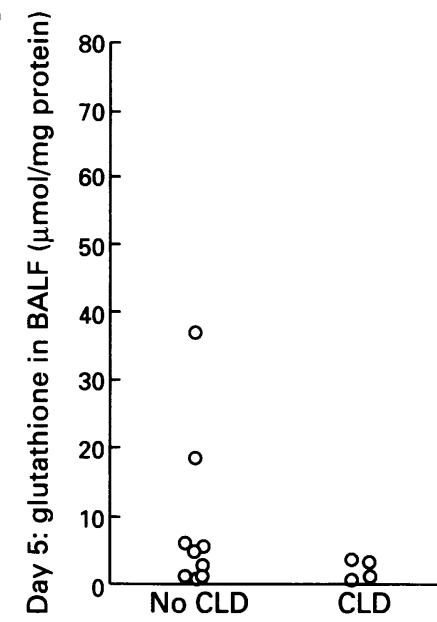

Concentrations of glutathione in BALF obtained on the first $(A, B)$ and fifth $(C, D)$ days of life adjusted and unadjusted for protein. Infants with chronic lung disease (CLD) had lower glutathione concentrations (unadjusted) on day $1(p<0 \cdot 01)$ but not day 5.

Table 1 Patient details. Values are mean (range)

\begin{tabular}{lccc} 
& $\begin{array}{l}\text { No } C L D \\
(n=27)\end{array}$ & $\begin{array}{l}C L D \\
(n=7)\end{array}$ & $\begin{array}{l}\text { Died before } \\
28 \text { days } \\
(n=13)\end{array}$ \\
\hline $\begin{array}{l}\text { Gestation (weeks) } \\
\text { Birth weight (g) }\end{array}$ & $\begin{array}{c}29 \cdot 9(25-34) \\
\text { Duration of oxygen treatment (days) }\end{array}$ & $\begin{array}{c}1384(650-2510) \\
14.6(0.5-58)\end{array}$ & $\begin{array}{c}26.5(24-31)^{\star} \\
1850(740-1650) \star\end{array}$ \\
\hline
\end{tabular}

${ }^{\star} \mathrm{p}<0 \cdot 05:$ no CLD $v$ CLD by Student's $t$ test.

Infants with CLD were of a lower gestational age and birth weight compared with those without CLD ( $p<0 \cdot 05$, table 1). Glutathione on the first day was lower in the group with CLD ( $p=0.003 v$ those without CLD; figure, table 2). After adjusting for protein, this difference did not reach significance $(p=0.09)$. Glutathione on the first day in infants dying before 28 days was no different from the group without CLD (3.9 $v 4.7 \mu \mathrm{mol} / \mathrm{l}, \mathrm{p}=0.68 ; 6.2 v$ $10 \cdot 1 \mu \mathrm{mol} / \mathrm{mg}$ protein, $\mathrm{p}=0 \cdot 82$ ).

On the fifth day, there were no differences in glutathione either before or after adjustment for protein between the groups with or without CLD (table 2).

\section{Discussion}

Glutathione was detected in the BALF and hence the epithelial lining fluid of all intubated premature babies. The significantly lower concentrations of glutathione on the first day in infants who subsequently developed CLD when measured directly in the BALF became only a trend when adjusted for protein. The ideal method of correcting for variations in epithelial lining fluid dilution in neonates is not known. We were unable to use the urea dilution ${ }^{9}$ because of the small sample volume. If epithelial lining fluid protein at birth is the same in all infants, adjusting for protein should be valid. There is little variation in first day epithelial lining fluid protein in infants with established respiratory distress syndrome. ${ }^{10}$ However, as respiratory distress syndrome is not a necessary prerequisite for CLD, ${ }^{11}$ we included infants irrespective of their respiratory diagnosis. In some of these newborn infants, significant pulmonary inflammation (and presumably high epithelial lining fluid protein) may be present. For example, prolonged rupture of the membranes increases both the numbers of BALF inflammatory cells and concentrations of epithelial lining fluid interleukin-6 at birth. ${ }^{12}$ The value of 'correcting' for protein is therefore debatable as epithelial lining fluid protein is not an independent marker of epithelial lining fluid volume. Although the degree of dilution in the epithelial lining fluid is unknown, concentrations of glutathione in the BALF of between 0.5 and $16.8 \mu \mathrm{mol} / /$ in this study, when compared with the plasma concentration of $0.9 \mu \mathrm{mol} / \mathrm{l}$ in healthy adults, ${ }^{13}$ suggest significantly higher concentrations of glutathione in the newborn infants' epithelial lining fluid compared with the plasma.

Differences in glutathione on the first day were seen after excluding infants dying before 28 days from the analysis. They were excluded as CLD cannot be reliably diagnosed before the first month of life. However, it is surprising that their glutathione concentrations were similar to those of the group without CLD. It is possible that early death is not associated with the type of pulmonary injury that leads to CLD or alternatively, severe early lung damage may release intracellular glutathione into the epithelial lining fluid.

As there was no correlation between gestational age and glutathione on the first day, the

Table 2 Sequential concentrations of glutathione in BALF. Values are mean (range)

\begin{tabular}{|c|c|c|c|c|c|c|}
\hline & \multicolumn{3}{|l|}{ Day 1} & \multicolumn{3}{|l|}{ Day 5} \\
\hline & $\begin{array}{l}\text { No } C L D \\
{[n]}\end{array}$ & $\begin{array}{l}C L D \\
{[n]}\end{array}$ & $p$ Value* & $\begin{array}{l}\text { No } C L D \\
{[n]}\end{array}$ & $\begin{array}{l}C L D \\
{[n]}\end{array}$ & $p$ Value ${ }^{*}$ \\
\hline $\begin{array}{l}\text { Glutathione in BALF } \\
(\mu \mathrm{mol} / 1)\end{array}$ & $\begin{array}{l}4 \cdot 7(0 \cdot 2-16 \cdot 8) \\
{[27]}\end{array}$ & $\begin{array}{l}1 \cdot 1(0 \cdot 5-3 \cdot 1) \\
{[7]}\end{array}$ & 0.003 & $\begin{array}{l}3 \cdot 7(0 \cdot 2-11 \cdot 1) \\
{[10]}\end{array}$ & $\begin{array}{l}2 \cdot 1(0 \cdot 5-5 \cdot 8) \\
{[5]}\end{array}$ & 0.69 \\
\hline $\begin{array}{c}\text { Glutathione in BALF } \\
(\mu \mathrm{mol} / \mathrm{mg} \text { protein })\end{array}$ & $\begin{array}{l}10 \cdot 1(0 \cdot 2-80) \\
{[26]}\end{array}$ & $\begin{array}{l}2 \cdot 8(0 \cdot 6-5 \cdot 4) \\
{[6]}\end{array}$ & 0.09 & $\begin{array}{l}8 \cdot 4(0 \cdot 3-37) \\
{[9]}\end{array}$ & $\begin{array}{l}2 \cdot 4(0 \cdot 7-3 \cdot 9) \\
{[4]}\end{array}$ & 0.45 \\
\hline
\end{tabular}

*Student's $t$ test: no CLD $v$ CLD after $\log _{10}$ transformation. 
lower concentrations of glutathione in infants with CLD cannot be explained by an effect of gestational age. The subsequent similarity in glutathione concentrations at day 5 between the groups with and without CLD is not necessarily surprising. Firstly, many infants with minimal lung disease were extubated and could not be lavaged. Secondly, an increased vulnerability to hyperoxic lung damage requires only glutathione depletion of less than 10 hours. ${ }^{5}$ Both the first and fifth day results are therefore compatible with the hypothesis that early pulmonary glutathione depletion predisposes the neonatal lung to oxidant damage.

The relationship between intracellular and extracellular (that is epithelial lining fluid) glutathione is poorly understood. Low extracellular concentrations of glutathione may just be a reflection of a more important intracellular depletion. However, human adult lung epithelial lining fluid does contain the necessary enzymes to prevent hydroxyl formation in the extracellular space. ${ }^{7}$ In addition, the low concentrations of glutathione in the epithelial lining fluid associated with adult respiratory distress syndrome suggest that extracellular concentrations are important in vivo. ${ }^{14}$ There are theoretical reasons why pulmonary glutathione could be depleted in some infants. For instance, as intracellular glutathione is dependent on the availability of cysteine, ${ }^{15}$ the lower cord cysteine concentrations seen as gestational age decreases ${ }^{16}$ may impair glutathione synthesis.

In conclusion, this study provides preliminary evidence that infants who develop CLD may have lower glutathione concentrations in their iung epithelial lining fluid on the first day of life, independent of their gestational age. However, it remains unclear whether glutathione in the BALF, corrected or uncorrected for protein reflects the actual concentration in lung epithelial lining fluid.

We thank Action Research for supporting this project.

1 Bancalari E, Sosenko I. Pathogenesis and prevention of neonatal chronic lung disease: recent developments. Pediatr Pulmonol 1990; 8: 109-16.

2 Farber JL, Kyle ME, Coleman JB. Biology of disease: mechanisms of cell injury by activated oxygen species. Lab Invest 1990; 62: 670-9.

3 Jenkinson SG, Marcum RF, Pickard JS, Orzechowski Z, Lawrence RA, Jordan JM. Glutathione disulfide formation occurring during hypoxia and reoxygenation of rat lung. F Lab Clin Med 1988; 112: 471-80.

4 Smith LJ, Anderson J, Shamsuddin M, Hsueh W. Effect of fasting on hyperoxic lung injury in mice: the role of glutafasting on hyperoxic lung injury in mice: the

5 Deneke SM, Lynch BA, Fanburg BL. Transient depletion of lung glutathione by diethylmaleate enhances oxygen toxicity. $\Im$ Appl Physiol 1985; 58: 571-4.

6 Fanburg BL, Deneke SM. Protein deficiency potentiates oxygen toxicity. Exp Lung Res 1988; 14: 911-9.

7 Cantin A, North SL, Hubbard RC, Crystal RG. Normal alveolar epithelial lining fluid contains high levels of glutathione. F Appl Physiol 1987; 63: 152-7.

8 Tee LBG, Boobis ARB, Huggett AC, Davies DS. Reversal of acetaminophen toxicity in isolated hamster hepatocytes by dithiothreitol. Toxic Appl Pharmacol 1986; 83: by dithio.hr $294-314$.

9 Grigg J, Arnon S, Silverman M. Fractional processing of sequential bronchoalveolar lavage fluid from intubated babies. Eur Resp f 1992; 5: 727-32.

10 Hallman M, Merritt TA, Akino T, Bry K. Surfactant protein A, phosphatidylcholine, and surfactant inhibitors in epithelial lining fluid. Am Rev Respir Dis 1991; 144 1376-84.

11 Edwards DK, Jacob J, Gluck L. The immature lung: radiographic appearance, course and complications. $A \mathscr{F} R$ 1980; 135: 659-66.

12 Grigg JM, Barber A, Silverman M. Increased levels of bronchoalveolar lavage fluid interleukin-6 in preterm bronchoalveolar lavage fluid interleukin- 6 in preterm ventilated infants after prolonged ruptir Dis 1992; 145: 782-6.

13 Beutler E, Gelbart T. Plasma glutathione in health and in patients with malignant disease. $f$ Lab Clin Med 1985; 105: 581-4.

14 Pacht ER, Timerman AP, Lykens MG, Merola AJ Deficiency of alveolar fluid glutathione in patients with sepsis and the adult respiratory distress syndrome. Chest 1991; 100: 1397-403.

15 Deneke SM, Fanburg BL. Regulation of cellular glutathione. Am f Physiol 1989; 257: L1 63-73.

16 Picone TA, Daniels TA, Ponto KH, Pitard WB. Cord blood tryptophan concentrations and total cysteine concentra-
tions. Fournal of Parenteral and Enteral Nutrition 1989; 13: tions. Foum 